\title{
A cultura na ponta do garfo: estética e hábitos alimentares na cidade de São Paulo - 1890/1920*
}

Denise Bernuzzi de Sant'Anna**

\section{Resumo}

Este artigo trata de algumas mudanças nos hábitos alimentares na cidade de São Paulo entre o final do século XIX e o começo do século XX. Novos restaurantes, cafés e padarias foram criados juntamente com novas exigências de higiene na produção e na venda de alimentos. Ao mesmo tempo, os costumes à mesa foram modificados de acordo com as diferenças entre homens $e$ mulheres. Desde então, por um lado houve a invenção de uma identidade gastronômica considerada típica dos paulistanos, mas atribuída, sobretudo aos homens de prestígio na cidade. Por outro, a valorização do gosto pela gastronomia ocorreu na mesma época em que começou a aumentar a exigência de regimes para emagrecer e um maior controle do peso corporal.

Palavras-chave: Hábitos Alimentares, Identidade, Dietas.

* Recebido para publicação em 28 de maio de 2012, aceito em 16 de junho de 2012. Texto inspirado na pesquisa (bolsa produtividade) financiada pelo CNPq sobre a alimentação e o peso dos corpos.

** Professora de História da PUC-SP. dbsat@uol.com.br

cadernos pagu (39), julho-dezembro de 2012:177-200. 
A cultura na ponta do garfo

Culture at the Tip of the Fork: Looks and Eating Habits in the City of São Paulo - 1890/1920

\begin{abstract}
This paper explores some changes in the eating habits of people who lived in the city of São Paulo between the late nineteenth and early twentieth centuries. New restaurants, coffee shops and bakeries were created along with renewed hygiene requirements for the production and sale of food. At the same time habits at the table during meals were modified according to male and female differences and taste. Since that period there was on the one hand, the invention of a gastronomic style, very typical of São Paulo's citizens, although it may be referred mainly to the elite or rich classes. On the other hand, the development of a peculiar taste for food occurred at the same time that diets to lose weight became increasingly popular together with a higher control over body weight.
\end{abstract}

Key Words: Eating Habits, Identity, Diets. 
O homem é apenas o que come, ou antes, o que digere. Todas as nossas funções dependem fatalmente do estomago, até as faculdades moraes (Diario Popular, 7/10/1901:1).

No começo do século passado, o crescimento comercial da capital paulista contribuiu para diversificar os alimentos vendidos em armazéns, tascas, cafés, padarias e restaurantes. Nas Atas da Câmara do município e na imprensa local, o valor da alimentação considerada nutritiva e higiênica ganhou destaque, assim como os hábitos alimentares capazes de distinguir o que era moderno de tudo o que resistia às mudanças julgadas necessárias ao progresso de São Paulo. O esforço em alimentar-se conforme o figurino de uma vida metropolitana, ainda balbuciante entre os paulistanos, devia respeitar as novas regras de asseio em vigor, mas também as diferenças entre espaço rural e meio urbano, hábitos masculinos e deveres femininos. Naquela época, a noção de risco alimentar era compreendida como típica de um tempo que devia ser superado. A crítica à falta de asseio dos doces e salgados fabricados por vendedores ambulantes abria a possibilidade de justificar o desejo de submeter todo o comércio de alimentos ao pagamento de impostos. Mas, ao mesmo tempo, ganhava relevo a necessidade de associar a alimentação à invenção de uma identidade paulistana inovadora, cuja essência era o cosmopolitismo do gosto e das aparências.

Essa invenção dependia, em grande medida, de três tendências em desenvolvimento naqueles anos: em primeiro lugar, a adoção de novos hábitos de limpeza na fabricação, no transporte e na venda de alimentos. Os conselhos para o asseio insistiam cada vez mais habitualmente na necessidade de se precaver contra a contaminação causada por "germes e bactérias" presentes no mundo invisível a olho nu. O jornal Diário Popular esteve entre aqueles que intensificaram a difusão de longas matérias sobre a necessidade de manter matadouros, açougues e estábulos limpos e bem equipados. Em outros jornais, as 
A cultura na ponta do garfo

desconfianças em torno do comércio de carnes verdes, pescados e leite tornaram-se rotina.

Em segundo lugar, muitas daquelas notícias eram acompanhadas por conselhos sobre como conhecer os alimentos destinados ao apuro da raça, da moral, da graça feminina e da força masculina: a multiplicidade de suspeitas perante a comida era equivalente ao número crescente de expectativas criadas a seu respeito. Se a boa alimentação tinha o poder de curar as "doenças da alma", era evidente que ela também modificava a estética corporal, podendo transformar o feio em belo. E é justamente a partir do século XX que uma atenção inusitada ao volume dos corpos vinculou-os ao ensejo de modernização, colocando na ordem do dia a necessidade de dietas para engordar ou emagrecer.

Em terceiro lugar, algumas das preocupações com a nutrição difundidas pela imprensa do começo do século passado insistiam numa alimentação destinada aos paulistanos considerados "da gema", respeitosa das especificidades dos gêneros masculino $e$ feminino. Havia, por exemplo, a comida julgada específica às mulheres em seus períodos de "resguardo", assim como os alimentos suspeitos de dotarem o homem de uma delicadeza mais afeita ao mundo feminino. Juntamente com uma gama de alimentos destinados aos doentes, inválidos e neurastênicos, a imprensa daqueles anos divulgava dietas para melhorar as aparências das mulheres, as quais nem sempre procuravam o emagrecimento.

As diferentes atribuições dos alimentos entre os sexos não eram novidades nem exclusividades da cidade de São Paulo. No entanto, no período estudado, elas ganharam uma visibilidade até então inusitada na imprensa paulista e serviram para modificar e fortalecer algumas distinções entre mulheres gordas e magras, entre homens robustos e fracos. 


\section{O espaço da casa, as receitas e a alimentação}

Quase tudo se fazia em casa: a gente matava porco, fazia linguiça, abria panos de carne, salgava e guardava pro mês inteiro, tirava os ossos e vendia pras fábricas de botão (...) O pão a gente fazia em casa (...) Plantava feijão, plantava arroz, a gente colhia e quando não tinha máquina de beneficiar por perto a gente socava no pilão abanava com a peneira, aquele arroz catetinho que era meio roxinho, botava umas palhas, um pouco de fubá, limpava, ficava branco (Bosi, 1987:297).

Algumas memórias sobre a vida paulistana durante as primeiras décadas do século XX ilustram um cotidiano permeado pelos afazeres de uma cultura mais rural do que urbana, dentro da qual a casa era um importante centro produtivo. Muitas roupas e boa parte da alimentação eram fabricadas no ambiente doméstico, assim como diversos instrumentos de trabalho e brinquedos. $\mathrm{O}$ embelezamento feminino, outro exemplo, tendia a ser uma experiência vivida em casa, diante de móveis denominados "toilette", que possuíam espelhos e ficavam dentro das alcovas que, antes do século XX, eram simples e pouco ventiladas (Oliveira, 2005:372). Progressivamente, as ilustrações da propaganda de dormitórios claros e arejados tornaram-se símbolos de prestígio e higiene. Dentro deles surgiram elegantes penteadeiras, próximas aos guarda-roupas, cujas portas possuíam espelhos retangulares. As penteadeiras entronizavam a mulher diante de si, facilitando a astuta mistura entre o prazer e o dever de se embelezar. Antes da década de 1930, a maior parte dos cosméticos ainda não era adaptada ao transporte em bolsas. As embalagens de vidro ou papelão tornavam os pós, tinturas e perfumes apropriados a ornar as penteadeiras. Estas e a maior parte dos cosméticos sugeriam o quanto o gesto de embelezar o rosto estava longe de ser uma banalidade, justamente numa época em que muitas mulheres ainda viviam grande parte do dia dentro ou em torno da própria moradia. 
A cultura na ponta do garfo

$\mathrm{O}$ quarto de dormir era também um lugar privilegiado para a realização do parto e para as mulheres viverem o período de resguardo. A canja era um dos pratos recomendados nessas condições, assim como o leite. A idade das parturientes variava, mas, desde o século XIX, era comum considerar que uma senhora de quarenta anos já era idosa. No entanto, nem todos sabiam a data do próprio nascimento (Camargo, 2007). Para ambos os sexos, a data do batismo tinha uma importância hoje esquecida, assim como o costume de fazer jejum na Semana Santa ou de tomar, anualmente, um purgante com a intenção de "limpar a máquina corporal".

Já no século XX, a importância dos remédios industrializados e da culinária baseada em ingredientes importados conquistou um lugar privilegiado na imprensa. É quando a arte de inventar pratos será divulgada como um traço não apenas de boa educação, mas também de modernidade. Zélia Gattai se lembra das receitas inventadas em sua casa e que exigiam compras quase diárias num armazém conhecido. Também se lembra do quanto o seu pai "era restrito em certas coisas: não admitia, por exemplo, que alguém estivesse ausente nas horas de refeição" (Gattai, 1995:148). Nas residências das famílias ricas, a função da sala de jantar, antes de ser absorvida pela copa, incluía a alimentação e o convívio familiar (Carvalho, 2008:25).

O uso do gás foi um elemento importante na mudança dos hábitos alimentares ao longo do tempo. $\mathrm{O}$ acesso aos fogões a gás estava longe de ser igualitário entre os paulistanos, mas, progressivamente, a propaganda impressa enfatizava a higiene possibilitada por este eletrodoméstico: comparado ao fogão a lenha, o fogão a gás era considerado higiênico e prático. Seu uso dependia da ligação à rede de gás, o que envolvia gastos com a instalação de tubulações nas residências. A Companhia de Gás, existente em São Paulo desde 1872, passou a investir em gás doméstico na década de 1930, mas, mesmo antes, já havia 
instituído cursos de culinária destinados a estimular as donas-decasa a aderir a esse tipo de abastecimento (Silva, 2002).

Se, como afirmou Barthes, a alimentação é um sistema de comunicação, o espaço doméstico representou ao longo do tempo um lugar privilegiado para esta comunicação ser expressa $e$ acolhida (Barthes, 1970). Mas a parte consagrada à produção das refeições nem sempre se limitou à cozinha. Até meados do século passado, ela se estendeu aos quintais de terra, aos córregos e à roça. Uma parte importante das receitas difundidas nos jornais da capital paulista pressupunha que as donas-de-casa deviam saber matar, depenar e desossar galinhas, criar porcos, cultivar frutas $e$ legumes. O saber feminino sobre a alimentação incluía, portanto, uma parte da produção agrícola, além da criação de diferentes animais. Aos homens, especialmente os mais pobres, esse saber também era comum, no entanto, a lida doméstica se concentrava no rol de tarefas preferencialmente femininas. Já a caça de perdizes e a pesca de peixes grandes eram atividades do sexo masculino, assim como a profissão de barqueiro, pois a cidade ainda possuía diversos córregos e rios a céu aberto.

No livro de memórias de Jacob Penteado, por exemplo, percebe-se o quanto os meninos estavam habituados a utilizar os riachos para a pesca e as travessuras cotidianas (Penteado, 2003:235-237). Naquele tempo, era comum encontrar meninas a brincar com suas bonecas ou a "fazer comidinha", enquanto os meninos se divertiam nas disputas em matagais, pontes e rios. A molecada paulistana alcançava o meio dos rios caudalosos, correndo o risco de afogamento na busca de riquezas imaginadas no fundo das águas. Esperava-se que uma boa menina não frequentasse tais paragens e mantivesse os pés bem fixos no solo firme (Sant'Anna, 2007:251-260).

Assim, a natação e a pesca eram consideradas atividades mais masculinas do que femininas. No entanto, diversas mulheres pobres frequentavam a beira dos rios Tamanduateí, Pinheiros e Tietê para realizar a pesca em peneiradas de lambaris e camarões de água doce, ou pitões, conforme se dizia. Estes lhes serviam 
para a fabricação de bolinhos vendidos em quiosques do centro urbano e para o consumo doméstico. Várias lavadeiras retiravam dos rios os ingredientes para a própria culinária. Os grandes peixes eram considerados frutos da aventura masculina enquanto que os pequenos tendiam a ser associados à labuta das mulheres. Os rios grandes ou os trechos mais caudalosos eram, aliás, batizados com nomes claramente viris, tendência essa que ajudava a mantê-los sob o domínio dos verdadeiros machos: "curva do cu" e "esquina do caralho" eram alguns dos nomes conhecidos entre os barqueiros (Sant'Anna, 2007:251-260).

Mas a necessidade de manter os homens dentro de jornadas julgadas moralmente salubres deu lugar a diferentes resoluções no âmbito da Câmara municipal. Entre 1880 e 1900, aumentou o número de projetos e resoluções sobre as condutas dos frequentadores de tascas, tavernas e botequins, entre outros lugares considerados afeitos à reunião de "ébrios, vagabundos e desordeiros". Numa dessas resoluções, ficou decidido que tais estabelecimentos deveriam fechar às 22 horas no verão e às 21 horas no inverno (Atas da Câmara, 14/01/1896:29-30). Tornava-se cada vez mais clara a necessidade de distinguir as tascas populares dos lugares de fino trato. Na mesma data, o parecer número 12 afirmou que: "só poderão conservar-se abertas diariamente até meia noite e em noites de espetáculo até uma hora, os restaurantes, casas de chopes e cafés julgados de primeira ordem" (id.ib.:30). Havia a suposição de que, nesses locais, os excessos bebedeiras, farras e freges - não ocorriam com facilidade. Além disso, nos espaços considerados de fino trato, as clientes apareciam acompanhadas. Já nas antigas tascas, as mulheres pobres podiam ser encontradas em grupos ou sozinhas. Elas circulavam entre ruas de terra, pontes e becos, possuíam, portanto um conhecimento geográfico sobre o conjunto da cidade que nem sempre fazia parte dos saberes das senhoras ricas. Já nos novos cafés e restaurantes inaugurados no final do século XIX, a maior parte da clientela era formada por homens, ora sozinhos, ora acompanhados por seus familiares. 
Desde então, os jornais paulistanos publicaram numerosos artigos destinados à divulgação de receitas. Por exemplo, em 1898, o jornal "A Noite" inaugurou uma seção dedicada à culinária. Tinha a intenção de atrair as donas-de-casa para as novidades em matéria de cozinha: "collecionar um excellente formulario de cosinha" seria doravante possivel se cada leitora guardasse as receitas publicadas, que incluíam doces, salgados $e$ licores (A Noite, 2/08/1898). Várias receitas utilizavam conservas, temperos e "enchidos" comprados nos armazéns de secos $e$ molhados. Essa iniciativa do jornal também supunha que as donas-de-casa deviam ser alfabetizadas, o que evidentemente excluía uma grande parcela da população que não fazia parte do mundo letrado.

O Correio Paulistano também começou a publicar uma seção intitulada "Entre a sopa e o café", numa época em que se insistia em novos horários para as refeições: a partir da última década do século XIX, o almoço servido dentro da cidade e principalmente para as elites locais começou a ser interpretado como uma refeição que se relacionaria com o sol a pino, enquanto que o jantar poderia ser servido depois das 18 horas. Esses novos horários exprimiam portanto um desejo de distinção entre os citadinos abastados considerados modernos e as famílias roceiras pouco acostumadas à vida urbana.

As receitas publicadas possuíam títulos inspiradores de devaneios gustativos e, ao mesmo tempo, reenviavam o leitor à diversidade de tradições culinárias, real ou imaginada, do estado paulista: "Creme de Bom Jardim", "Frango de Jaguary", "Pescada de Ubatuba", "Perdizes de Mogi-Mirim", "Pudim de Lorena", "Torta Ytuana", entre outros.

A preocupação em registrar e divulgar receitas sempre contou com a memória e a cultura oral. No entanto, desde 1880, com o aumento de novos restaurantes na cidade, a propaganda dos dotes culinários de seus proprietários conquistou maior espaço nos jornais. Ora, uma grande parte das receitas publicadas não registrava as medidas dos ingredientes utilizados da mesma 
A cultura na ponta do garfo

maneira que, mais tarde, será feito. Por exemplo, várias delas prescreviam "um bocado de manteiga" ou "uma boa quantidade de açúcar", sugerindo que os leitores sabiam o que significava "um bocado" e "uma boa quantidade". O que hoje seria considerado uma imprecisão, não o era necessariamente naquela época. Podia-se, numa mesma receita, recomendar o cozimento de uma carne por um quarto de hora e prescrever temperá-la com produtos segundo "o agrado do consumidor".

A difusão das receitas expressa algumas características típicas da alimentação valorizada pelos leitores daqueles anos. Por exemplo, a presença forte da carne de porco, o uso frequente do toucinho e de um cálice de vinho na preparação de diversos pratos. A referência a animais criados nos quintais também era comum, assim como o uso de ovos:

Frango de Jaguary - Toma-se um frango cortado em pedaços põe-se este sobre o lume n'uma panela com uma quarta de toucinho picado e um cará cortado em pedaços, com sal, salsa, folhas de cebola e pimenta comari; deixa-se ferver até ficarem cozidos; engrossa-se o molho com três gemas d'ovos e uma pitada de polvilho e duas colheres de sumo de limão e serve-se o frango (Correio Paulistano, 28/08/1899:2).

O tempo do cozimento nem sempre era registrado. Havia ainda uma grande quantidade de fogões a lenha além do pressuposto de que todos conheciam uma série de técnicas para o preparo de doces e salgados, certamente passadas oralmente entre as gerações e, sobretudo, entre mulheres. Mas com a crescente divulgação dessas receitas nos jornais, juntamente com a propaganda sobre os novos restaurantes e cafés da cidade, a atividade culinária passou a ser bem aceita na medida em que era um ofício prestigioso, e, como tal, tinha à frente um homem, responsável pela boa mesa. No mesmo ano em que a receita acima foi publicada, o dono de um restaurante localizado na rua 
Santa Tereza, chamado Ludgero, ofereceu uma "feijoada de arromba, dessas feijoadas completas, acepipe que começa na bela cabeça de porco e acaba... numa medonha indigestão para os que não sabem conter os excessos da gula"; tudo acompanhado por uma boa caninha (Diário Popular, 1/11/1899:1). Comer bem era uma experiência que devia espantar para longe o espectro da fome e da miséria. No final da década de 1910, algumas autoridades públicas defendiam a criação de cantinas escolares que vendessem diferentes alimentos, possibilitando refeições que não se limitassem ao usual pedaço de pão e à costumeira banana (id., 24/11/1911:1).

A presença na cidade de exímios cozinheiros, padeiros $e$ confeiteiros tendia a ser cada vez mais difundida como sendo um bom exemplo da modernidade paulista. A maior parte dos pratos e receitas divulgados pela imprensa das primeiras décadas do século XX tinha, portanto, o sexo masculino na liderança das cozinhas. Havia, por exemplo, pasteleiros conhecidos, tais como Henrique Jergen, que fazia seus quitutes na Casa do Braço de Ouro. Pastéis, empadas, croquetes de camarão, entre outras delícias, eram suas especialidades (id., 7/12/1899:1). Havia ainda vários padeiros renomados, assim como muitos homens proprietários de restaurantes sofisticados e luxuosos.

\section{Paulistano da gema}

mas o destino dos homens se decide é na cozinha (Perecin, 1990:67).

Entre o final do século XIX e o começo do XX, a expressão "paulistano da gema" não estava distante de algumas expectativas culinárias características do que se considerava uma alimentação moderna, saudável e saborosa. Em diversas propagandas de restaurantes, bares e cafés da cidade, os paulistanos tendiam a ser considerados detentores de um duplo saber gastronômico: cultivavam hábitos tradicionais e, ao mesmo tempo, conheciam as 
A cultura na ponta do garfo

novidades julgadas típicas do mundo moderno. Ser verdadeiramente paulistano significava sentir-se à vontade diante de uma culinária com raízes rurais e uma outra considerada mais afeita aos costumes urbanos. Portanto, era necessário apreciar os secos e molhados vendidos nos armazéns do centro urbano, mas também os produtos importados da Europa. Paulistano que se prezasse gostava de feijão, charque, empadas de camarão, mas igualmente de bebericar um "fino Porto", lambiscar talhadas de presuntos e outras iguarias importadas. Conjugar harmoniosamente esses dois universos - o local e o estrangeiro aparecia na imprensa como um atributo prestigioso, "típico dos paulistanos". Mas essa qualidade tendia a ser atribuída e esperada especialmente quando se tratava do sexo masculino.

No caso das mulheres, havia, em primeiro lugar, uma preocupação evidente com os alimentos que pudessem acentuar uma suposta tendência à melancolia. Considerada a mãe de todas as fraquezas, a melancolia era uma palavra utilizada quando se tratava de anunciar os principais perigos que rondavam a mocidade das décadas de 1910 e 1920, e, em particular, a vida das donzelas. Numa matéria publicada na revista A Cigarra, por exemplo, esse mal, considerado figura conhecida em muitos países, podia ser combatido com banhos de mar. Estes, afirmava o texto, "são sempre propícios às mulheres", pois elas podiam facilmente sucumbir nos labirintos melancólicos, alheios aos chamados masculinos (A Cigarra, 30/03/1914:8). A "dyspepsia", outro exemplo, aparecia na imprensa como uma doença mais comum ao sexo feminino e podia ser causada por uma alimentação julgada imprópria. $\mathrm{O}$ consumo do feijão, por exemplo, era, segundo um médico de 1898, um grande inimigo da saúde das moças (Diário Popular, 21/01/1898:1).

As propagandas de remédios para combater a fraqueza física feminina se avolumaram a partir da década de 1910 e, várias vezes, elas centralizaram a atenção sobre a dificuldade julgada "típica do sexo frágil" de conjugar a faculdade de pensar àquela de ser fértil e gerar filhos saudáveis. As sopas e os caldos eram 
considerados alimentos propícios à circulação dos humores femininos, além de serem compreendidos como uma precaução eficaz contra as friagens e também as febres. Antes de 1900, acreditava-se que febres e friagens eram problemas mais graves quando ocorriam no organismo das mulheres. A seguir, essa preocupação vai se somar ao medo de resfriar os pulmões. Supunha-se que a temperatura do corpo feminino era bastante susceptível de "destemperar". Apesar dos trabalhos pesados realizados por muitas mulheres na roça, dentro de casa $e$, a seguir, nas primeiras fábricas paulistas, diversos textos publicados na época ainda consideravam o corpo feminino algo mais complicado e frágil do que o organismo masculino. Na verdade, a noção de fragilidade tendia a ser traduzida em termos de imprevisibilidade. O corpo da mulher possuiria, assim, dimensões difíceis de controlar e de manter em equilíbrio, o que facilitou a associação dos homens à qualidade de variar e de inovar na alimentação.

É preciso lembrar que, embora conhecer a variedade alimentar fosse uma qualidade presente em outras cidades brasileiras e esperada de ambos os sexos, em São Paulo tratava-se de aplicá-la principalmente aos homens frequentadores dos cafés do centro urbano e que se identificavam como sendo pessoas de prestígio e poder. Ora, desde a década de 1880, o sentimento de ser da cidade de São Paulo tendeu a suplantar a antiga ideia de fazer parte de uma de suas paróquias ou freguesias. Na medida em que a cidade crescia, os poderes públicos insistiam na importância de percebê-la em seu conjunto. Para uma minoria letrada, o "paulistano" era uma espécie de adjetivo capaz de diferenciar a vida urbana daquela considerada excessivamente rural, os tempos republicanos da época imperial. E os hábitos alimentares assim como o gosto culinário podiam confirmar ou não essa expectativa.

Mas a repartição das preferências à mesa também respeitava as distinções entre os sexos. Os paulistanos expressavam seus conhecimentos gastronômicos principalmente dentro de 
A cultura na ponta do garfo

restaurantes, bares e cafés, locais nos quais a presença de senhores e rapazes permanecia dominante embora, no trabalho de preparar os alimentos, era comum encontrar mulheres. Aos homens era atribuído o gosto principalmente das bebidas alcoólicas, dos enchidos e carnes. É sobre as carnes, aliás, que um grande debate teve lugar na capital paulista durante as duas últimas décadas do século XIX, envolvendo suspeitas sobre a limpeza dos matadouros, açougues, sobre a qualidade do transporte de carnes verdes e toucinhos, colocando em evidência as opiniões de higienistas, políticos e escritores sobre a salubridade urbana e a nutrição da população (Diario Popular, 4/05/1886:2). Havia, ainda, uma tendência relativamente comum na imprensa em publicar notícias sobre envenenamentos. Segundo os jornais, eles eram causados ora pela ignorância, ora pela ganância: misturar água ao leite para fazê-lo render ou, colocar substâncias suspeitas em doces e salgados eram críticas comuns na época. Quanto à ignorância, essa tendia a recair, principalmente, sobre as mulheres pobres. Por exemplo, em 1899, uma senhora chamada Josephina Charrettim ingeriu cogumelos colhidos no caminho para o bairro de Sant'Anna, juntamente com suas filhas. Todas passaram muito mal (Diario Popular, 19/12/1899:1).

A identidade de uma São Paulo asseada também era construída por meio do crescimento das casas comerciais ligadas à alimentação. Nos anúncios publicados na imprensa local, as padarias e confeitarias consideradas limpas e finas estavam, em geral, associadas a proprietários cujos nomes evocavam respeito e consideração. Por exemplo, havia o senhor Ernesto Magnani, dono de uma padaria que desde 1885 era conhecida pela venda de "magníficos craknelles" e de um pão denominado "especial"; o senhor Carlos Pereira, proprietário da Padaria Francesa, por muitos anos, situada no Largo do Mercadinho e, a seguir, reaberta no Largo da Sé, era conhecido por ser especialista na venda de um "esplendido sortimento de doces seccos, biscoutos e outros artigos", tais como as torradinhas de erva-doce, os "melindres portugueses" e os "bolos de amor" (Diario Popular, 10/10/1885:1; e 
1/12/1887:4). Vários exemplos similares a estes foram difundidos pelos jornais, juntamente com a propaganda de novos restaurantes especializados em oferecer, com garbo e distinção, pratos hỉbridos, resultantes de diferentes influências culinárias.

No entanto, era fundamental destacar a suculência dos pratos servidos. O Café América, à rua Quinze de Novembro, era divulgado como sendo um "restaurant a la carte - cozinha de primeira ordem - com finas e suculentas iguarias" (A Noite, 7/05/1898:1). O adjetivo "suculento" combinava perfeitamente com a ideia de refinamento. Considerada uma qualidade imprescindível à saúde, a suculência devia constar na maior parte dos cardápios. Mas, no caso feminino, havia a tendência em requisitar a suculência alimentar principalmente quando era necessário curar fraquezas, magrezas insistentes, além de algumas doenças. Também era utilizada para se referir às dietas durante o resguardo das parturientes. Ou seja, uma refeição suculenta era amplamente apreciada, mas havia maior facilidade de aconselhála aos senhores e rapazes. Para o sexo feminino, a suculência devia ser contrabalançada com alguma frugalidade.

Contudo, em 1902, um projeto de autoria de Antonio Prado se tornou um grande foco de discussões dentro da Câmara Municipal. Prado propôs a criação de uma Escola Pratica de Pomologia e Horticultura e, segundo os pareceres das comissóes de Higiene da época, a proposta era muito boa porque contribuía para afirmar a diversidade à mesa e melhorar a saúde dos paulistanos. Chegou-se mesmo a dizer que uma dieta vegetariana produzia indivíduos mais formosos. E, ainda, que os animais carnívoros eram maus, perversos e estúpidos (Atas da Câmara, 16/04/1902:82). A referida Escola foi extinta cinco anos mais tarde sob a alegação de que seus resultados foram pequenos diante das expectativas que justificaram a sua criação (id., 8/03/1912:65-74).

As refeições julgadas civilizadas, dignas de um paulistano da gema, deviam, portanto, incluir frutas e verduras. Mas essa necessidade afirmada por Antonio Prado e outros homens influentes na cidade não era facilmente acatada pela população 
A cultura na ponta do garfo

cuja alimentação julgada forte e saudável contava sobretudo com a presença da carne de porco. Além disso, em repúblicas e pensões de estudantes, o picadinho com carne era um prato bastante apreciado, conhecido no final do século XIX como sendo característico do gosto paulista (Monteleone, 2010:48-49).

As antigas feiras livres foram também consideradas uma espécie de vitrine da fartura alimentar que todo paulistano devia valorizar. No começo do século passado, elas não tinham homogeneidade em relação à qualidade dos produtos ou à apresentação dos mesmos. Na maior parte das vezes, as frutas e verduras eram expostas sobre o chão, em pilhas mais ou menos organizadas segundo cada tipo de produto. Alguns tabuleiros feitos de madeira eram utilizados para expor doces e salgados. Em 1914, um ato do Prefeito Washington Luiz reconheceu oficialmente a existência das feiras, ao mesmo tempo em que foram estabelecidas "Cozinhas Econômicas" no Brás (Morse,1970:283).

Quando um novo mercado municipal foi construído, em 1933, as feiras já haviam conquistado terreno em diferentes bairros e o comércio ambulante, de víveres e outros produtos alimentícios, não se limitava mais às ruas centrais "para dentro das pontes", conforme se dizia antes da República. Elas, juntamente com o novo mercado, serviram para afirmar a capacidade da cidade de se relacionar com outras regiões do estado: frutas, carnes, legumes e cereais vindos do interior eram comercializados na capital, em suas feiras e no grande mercado.

\section{A capital gastronômica e a voga do emagrecimento}

Justamente quando São Paulo começou a ser ilustrada na imprensa como a capital da boa mesa, na propaganda impressa $e$ nas reportagens sobre embelezamento, teve início uma valorização inusitada das silhuetas esguias e longilíneas, resultantes de dietas para emagrecer. Tudo se passa como se, desde então, um perturbador paradoxo não cessasse de crescer e, até certo ponto, confundir os comensais: por um lado, aumentava a incitação ao 
prazer e às alegrias contidas no ato de comer doces e salgados, ilustrados de modo extremamente atraente pela propaganda. Por outro, aumentava também o número de regimes para emagrecer, assim como a ênfase na necessidade de reduzir o peso e o volume do corpo.

A década de 1920 representou apenas o começo dessa tendência paradoxal, hoje presente em diferentes sociedades. $\mathrm{Na}$ capital paulista, a incitação ao prazer alimentar teve como grande marco a realização da primeira exposição industrial de laticínios, em 1925. Ela ocorreu no Palácio das Indústrias. A alimentação foi ali considerada uma questão de afirmação das potências regionais e, logo a seguir, de identidade das raças e da Nação. Promessa de saúde, mas também de grande satisfação, a comida se tornou desde então uma grande vedete da propaganda impressa.

Mas a invenção de São Paulo como lugar privilegiado da gastronomia teve várias etapas ao longo do último século, que incluíram muitos costumes antigos ou oriundos da roça (Souza, 6:1921). O consumo do charque, por exemplo, era comum em residências pobres e ricas (A Noite, 30/06/1898:3). Interessante observar que, no final do século XIX, havia um tipo de alimentação considerada boa e apropriada a ricos e pobres: de origem ou influência portuguesa, ela consistia nos enchidos de vários tipos de carne. As tainhas em salmoura, importadas do Rio Grande do Sul em barris, também faziam sucesso. Vários anúncios confirmavam a preferência pela influência portuguesa na culinária:

Ali muito perto do novo Frontão, quem não conhece a casa das petisqueiras à Portugueza! Que bellos bifes, que suculentas canjas e que vinho especial! Quem uma vez vai jantar na rua da Boa Vista, 26, contrae o habito e nunca mais o abandona (A Noite, 17/02/1898:2).

Nessa época, a expressão "população paulistana" ganhava visibilidade na imprensa e o casamento entre nutrição, estética $e$ progresso social conquistava a atenção da propaganda e da 
A cultura na ponta do garfo

medicina. Mas a ideia de uma cidade moderna em sua alimentação implicava também a adoção de dietas. No livro de Dante Costa (1951), por exemplo, consagrado às relações entre boa alimentação e progresso nacional, o combate à desnutrição $e$ aos maus hábitos alimentares significava um passo importante rumo à modernização do país. Desnutrição implicava atraso social e nacional, sendo representada segundo o antigo imaginário da fome e da miséria. Para combatê-la, várias vezes se recorreu à produção de cartilhas e guias nutricionais (Rodrigues, 2011).

A influência estrangeira também interferiu nas concepções regionais de nutrição. Em 1916, a American Dietetic Association elaborou os primeiros guias nutricionais para classificar os alimentos em grupos. Tais guias tornaram-se uma referência importante para as políticas de saúde pública em diversos países, inclusive no Brasil. Eles veiculavam orientações sobre uma dieta considerada "cientificamente balanceada". No entanto, a maior parte dos conselhos sobre dietas nutritivas, consideradas racionais, dirigia-se às mulheres. No começo do século passado, cinco tipos de nutrientes eram básicos para uma boa alimentação: carboidratos, lipídeos, proteínas, minerais e ácidos orgânicos. No caso feminino, era preciso uma quantidade menor desses ingredientes. Por um lado, a mulher desnutrida representava a constituição de uma raça fraca. Mas, por outro, era preciso muito cuidado para não atribuir-lhe um caráter excessivamente másculo.

Esse temor estava presente nos conselhos publicados nas revistas mundanas e em alguns artigos escritos por médicos. Evidentemente a desnutrição sempre manteve uma forte relação com a carestia dos gêneros alimentícios. Carestia, pobreza e raquitismo formavam um trio amedrontador. Raquitismo implicava o emagrecimento súbito, a fraqueza física e mental ou simplesmente o fato de ser desprovida de atrativos para o sexo oposto. Mas o sentido dos regimes daqueles anos difere bastante daquilo que se conhece sobre as dietas atuais. Pois os líquidos e os legumes, por exemplo, eram considerados propiciadores de uma leveza espiritual desaconselhável para quem enfrentava 
situações difíceis. Havia textos que também associavam os movimentos bruscos a certas moléstias ou a comidas específicas: para os cardíacos, era aconselhado "não andar de carro, nem de cavallo, nem a pé" e sempre alimentar-se com "frango, carneiro, leitão magro, biscoitos finos, vinhos finos, aves frescas, fructas variadas" (Diário Popular, 17/09/1901). Com o passar dos anos, as dietas tenderam a incluir o consumo de medicamentos fartamente divulgados pela propaganda impressa. Evidentemente, a modernidade já estava associada às silhuetas juvenis e ágeis, exemplarmente divulgadas pelo cinema. Mas a realidade da alimentação e dos corpos ainda vinculava a saúde à fartura da comida julgada forte, promotora de corpos robustos e roliços. Mesmo assim, a partir de meados da década de 1910, diversos textos sobre os malefícios do excesso de volume corporal começaram, pouco a pouco, a marcar presença nos jornais $e$ revistas da capital.

Essa propaganda contrária ao peso e ao volume do corpo ocorreu ao mesmo tempo em diferentes países. Segundo um dos historiadores especialistas na história do peso corporal, nos Estados Unidos, "a batalha contra a gordura" teve início entre as décadas de 1890 e 1910 (Stearns, 2002:11-12). Tratava-se de um combate sobretudo feminino. Antes do aparecimento das Gibson Girls, as imagens das jovens belas publicadas na imprensa norteamericana e na literatura erótica exibiam uma variedade de formas físicas maior do que aquela vigente depois de 1900. Segundo Sterns, na década de 1920, o peso corporal ganhou uma atenção até então desconhecida: nos consultórios médicos, escolas e concursos de beleza o hábito de pesar o corpo passou a ser uma banalidade normalizada e necessária. A historiadora Hillel Scwhartz, outro exemplo, pesquisou numerosos textos norteamericanos sobre regimes de emagrecimento $e$ historicizou a positividade progressiva atribuída à magreza desde o final do século XIX. Segundo ela, a cultura da magreza transformou a noção de peso corporal num índice privilegiado para marcar as identidades humanas (Scwhartz, 1986). Esta tendência ocorreu na 
A cultura na ponta do garfo

medida em que os criminologistas passaram a considerar o peso como um indicador do caráter de cada indivíduo suspeito $e$ quando as empresas de seguro, especialmente depois da década de 1920, decidiram fazer uso do peso dos corpos para designar as especificidades morais de cada pessoa.

Na França, a década de 1920 também foi um marco importante na história do emagrecimento e da luta contra a gordura. Segundo o historiador francês Georges Vigarello, é a partir dessa época que "a amplitude abdominal se democratizou" entre os franceses $e$ a velha tradição de atribuir a gordura aos ricos e a magreza aos pobres sofreu uma inversão: estes últimos adquiriram "bruscamente um volume físico que eles não possuíam até então". (Vigarello, 2010:252). Na mesma direção, a historiadora Julia Csergo (2009:14-32), especialista na história do corpo (autora de um livro sobre a higiene durante o século XIX e, mais recentemente, pesquisadora sobre a obesidade e a alimentação), mostrou que a criação da figura do obeso, como aquele que possui uma identidade específica, diferente do gordo, é datada historicamente. Poder-se-ia dizer que ela nasceu no final do século XIX. No entanto o obeso adquiriu consistência enquanto problema histórico algumas décadas mais tarde. É quando a obesidade foi incluída no território de uma vasta gama de patologias e, portanto, dos tratamentos médicos.

No Brasil, a propaganda de medicamentos e alimentos considerados bons para emagrecer durante os anos 20 ainda era menos importante do que aquela destinada aos produtos para engordar e criar robustez. Apesar do aumento de anúncios para cintas modeladoras destinadas às mulheres e da valorização de esportes que demandavam uma silhueta leve e aerodinâmica, a beleza corporal ainda estava associada a alguma corpulência. Os regimes recomendados ainda não haviam declarado guerra aberta contra o açúcar e, muitas vezes, não detalhavam a quantidade dos alimentos que deviam ser consumidos. Comparados com as dietas atuais, eles eram genéricos e vagos, limitando-se a enfatizar que uma mulher não devia comer de modo exagerado. 
Mas, a história do corpo é sempre menos linear do que se pode imaginar. Assim, também é verdade que ser gordo significava, principalmente, possuir uma "pança majestosa", farta $e$ bem proeminente. E, nesse aspecto, a diferença entre homens $e$ mulheres era grande: enquanto que, para eles, a barriga grande podia ser um sinal de formosura e poder, para elas, a beleza já demandava uma cintura fina e um ventre pouco saliente. $\mathrm{O}$ encanto floral, que durante décadas foi esperado das mulheres, exigia-lhes uma cintura cuja finura facilitava o enlace masculino, quase como se elas fossem de fato flores à espera de serem colhidas para, a seguir, reinarem como rosas num jardim doméstico. Mesmo com a moda dos vestidos retos que dificultavam a visão da cintura fina, a imagem de uma mulher-flor continuou a valorizar a leveza corporal feminina, oposta à presença de ventres avantajados. Ou seja, à primeira vista, a batalha contra a gordura teria sido mais exigente para com as mulheres. Isto não significa contudo que os homens pudessem folgar diante da ampliação de seus volumes corporais. Para eles, havia outras exigências, como aquela de transformar boa parte do corpo em massa rígida, musculosa, vigor indicativo de um outro sustentáculo do esperado orgulho viril. A quantidade significativa de anúncios de produtos à base de ferro, destinados aos homens do começo do século, além dos fortificantes e diversos tipos de elixir para o sangue, confirmavam, diariamente, a necessidade de investir no corpo masculino de modo a torná-lo forte $e$ sexualmente apto à reprodução.

Mas foi somente depois da década de 1930 que a gordura passou a ser amplamente entendida como algo nefasto, um peso morto, uma inutilidade a ser eliminada ou transformada em músculo (Zucon, 2003). Desde então, novas exigências pousaram sobre o antigo imaginário da mulher graciosa e do homem viril: exigências que hoje, diferentemente da década de 1920, conhecem os numerosos distúrbios alimentares e uma vasta gama de riscos apresentados pela obesidade. E, finalmente, exigências que dependem, bem mais do que no passado, da liberdade de 
A cultura na ponta do garfo

construir para si um corpo que seja ao mesmo tempo belo, forte e jovem; um corpo delineado segundo um regime de vida muitas vezes cruel, delicioso, excessivo ou arriscado. Pois a comida tendeu a se tornar, desde o século passado, uma das principais verdades produtoras da identidade individual. Juntamente com o sexo, ela passou a definir o caráter e o modo de vida de cada um $e$, em particular, das mulheres.

Não por acaso, desde as últimas décadas, as misses, top models e outras celebridades consideradas referências publicitárias de beleza divulgam o que comem, como se alimentam, quais dietas preferem adotar. Diferente das musas cinematográficas da década de 1920, cujas falas se concentravam sobre seus amores, as beldades atuais contam com grande naturalidade seus hábitos alimentares e o modo como tratam da própria saúde. A construção de uma "imagem de marca" depende hoje não apenas do modo como uma mulher se comporta na cama, mas, também de suas preferências à mesa. Os homens famosos também falam sobre seus regimes e excessos alimentares, mas são elas, sobretudo, que "confessam" o detalhamento de dietas produtoras do que hoje se convencionou chamar de boa forma. Trata-se de uma antiga distinção entre homens e mulheres, sem dúvida, agora atualizada sob uma espécie de verdade, que às vezes parece natural e tipicamente feminina.

Mas a construção dessa verdade está fortemente presente na história de todos: "digas o que comes e eu te direi quem és." Para o bem e para o mal, a comida se tornou uma importante insígnia dos desejos íntimos e do caráter de cada um, mesmo quando não se é mais paulistano da gema e mesmo quando o saber e o sabor teimam em habitar zonas distintas da cidade ou de uma mesma vida.

\section{Referências bibliográficas}

BARTHES, Roland. Pour une psychosociologie de l'alimentation. Cahier des Annales, n 28, 1970. 
BosI, Ecléa. Memória e sociedade. Lembranças de velhos. São Paulo, Unesp, 1987.

CAMARGO, Luís Soares de. Viver e morrer e São Paulo. A vida, as doenças e a morte na cidade do século XIX. Tese de Doutorado, PUC-SP, São Paulo, 2007.

CarvalHo, Vania Cameiro de. Gênero e artefato, São Paulo, Edusp, 2008.

CostA, Dante. Alimentação e progresso: o problema do Brasil. Rio de Janeiro, SAPS, 1951.

CSERGO, Julia. Quand l'obésité des gourmands devient une maladie de civilisation. Le discours medical 1850-1930. In: CSERGO, J., Trop Gros? L'obésité et ses représentations. Paris, Autrement, 2009.

GATTAI, Zélia. Anarquistas graças a Deus. Rio de Janeiro, Record, 1995.

LEMOS, Carlos A.C, A República ensina a morar (melhor). São Paulo, Hucitec, 1999.

MONTELEONE, Joana. Sabores urbanos. Alimentação, sociabilidade e consumo. São Paulo, Alameda, 2010.

MORSE, Richard M. Formação histórica de São Paulo (de comunidade à metrópole). São Paulo, Difel, 1970.

OliveIRA, Maria Luiza Ferreira de. Entre a casa e o armazém. Relações sociais e experiência da urbanização. São Paulo, 1850-1900. São Paulo, Alameda, 2005.

PENTEADO, Jacob. Belenzinho, 1910 (retrato de uma época). São Paulo, Carrenho, 2003.

Perecin, Marly T.G. Candeias em espelho d'água (1777- 1845). São Paulo, Loyola, 1990.

Sant'AnNA, Denise Bernuzzi de. Cidade das águas. Usos de rios, córregos, bicas e chafarizes em São Paulo (1822-1901). São Paulo, Senac, 2007.

SCWHARTZ, Hillel. Never satisfied: a cultural History of Diets, fantasies and fat. New York, Free Press, 1986.

SILVA, João Luiz Máximo da. O impacto do gás e da eletricidade na casa 
A cultura na ponta do garfo

paulistana (1870-1930): estudos de cultura material no espaço doméstico. Dissertação de Mestrado, FFLCH, USP, São Paulo, 2002.

SouzA, Wanderley. Ensaios de calorimetria alimentar. Boletim do Instituto de Higiene, 6, 1921.

STERNS, Peter N. Fat History. Bodies and beauty in the Modern West. New York, University Press, 2002.

Vigarello, Georges. Histoire de l'obésité, du Moyen Age au XXème siècle. Paris, Seuil, 2010.

ZuCON, Otavio. Da corporalidade, concepções médicas sobre a forma corporal. Dissertação de Mestrado, UFSC, Florianópolis, 2006. 